\title{
Analysis for the Sorption Kinetics of Ag Nanoparticles on Natural Clinoptilolite
}

\author{
Alvaro Ruíz-Baltazar, ${ }^{1}$ Simón Yobanny Reyes-López, ${ }^{2}$ Oswald Tellez-Vasquez, ${ }^{1}$ \\ Rodrigo Esparza, ${ }^{1}$ Gerardo Rosas, ${ }^{3}$ and Ramiro Pérez ${ }^{1}$ \\ ${ }^{1}$ Centro de Física Aplicada y Tecnología Avanzada, Universidad Nacional Autónoma de México, Boulevard Juriquilla 3001, \\ 76230 Santiago de Querétaro, QRO, Mexico \\ ${ }^{2}$ Instituto de Ciencias Biomédicas, Universidad Autónoma de Ciudad Juárez, Envolvente del PRONAF y Estocolmo s/n, \\ 32300 Ciudad Juárez, CHIH, Mexico \\ ${ }^{3}$ Instituto de Investigaciones Metalúrgicas, UMSNH, Edificio U, Ciudad Universitaria, 58000 Morelia, MICH, Mexico
}

Correspondence should be addressed to Simón Yobanny Reyes-López; yobannyr@yahoo.com.mx

Received 14 June 2015; Accepted 13 September 2015

Academic Editor: Joseph S. Poon

Copyright (C) 2015 Alvaro Ruíz-Baltazar et al. This is an open access article distributed under the Creative Commons Attribution License, which permits unrestricted use, distribution, and reproduction in any medium, provided the original work is properly cited.

\begin{abstract}
The kinetic adsorption behavior of silver nanoparticles deposited on a natural zeolite from Oaxaca is presented. Theoretical models as Lagergren first-order, pseudo-second-order, Elovich, and intraparticle diffusion were employed and compared with experimental data obtained by atomic absorption spectrophotometry technique. Correlation factors $R^{2}$ of the order of 0.99 were observed. Analysis by transmission electron microscopy revealed that the silver nanoparticles were homogeneously distributed on the zeolite. Additionally, chemical characterization of the material was carried out through a dilution process with lithium metaborate. An average value of 9.3 in the $\mathrm{Si} / \mathrm{Al}$ ratio was observed and related to the kinetic adsorption behavior of the zeolite.
\end{abstract}

\section{Introduction}

Natural zeolites have been extensively studied due to their structural characteristics and physicochemical properties. These minerals present great porosity and a significant cation-exchange capacity [1]. Because of this, natural zeolites offer a wide range of applications; one of the most notable is the removal of contaminant ions in water and soil $[2,3]$. It is reported that natural zeolites, specifically clinoptilolite, have been used in the removal of $\mathrm{Mn}, \mathrm{Cu}, \mathrm{Ar}, \mathrm{Pd}, \mathrm{Cd}$, and $\mathrm{Zn}$ [46]. However, it is important to study the rate of adsorption of these species, in order to provide the optimum conditions for the adsorption process. The nature of the sorption process will depend on physical or chemical characteristics of the adsorbent systems and the system conditions. The most commonly used kinetic expressions to explain the solid/liquid adsorption processes are the pseudo-first-order kinetics and pseudo-second-order kinetic model [7-10]. A good number of works were reported where the modifications of these natural clays with nanoparticles were produced to carry out the adsorption of metals from aqueous solutions [11, 12]. These minerals offer low cost effective supports for nanoscale entities. The reactivity of nanosized zero valent metals like $\mathrm{Ag}$ and the high cation-exchange capacity of the zeolites represent a potential alternative for remediation applications $[5,11]$. However, specific studies about kinetics of adsorption of nanoparticles on clinoptilolite have not been explored thoroughly. In this research, the chemical characterization and the synthesis methodology of the composite of silver nanoparticles AgNPs-zeolite are presented. Additionally, we present a detailed analysis of the kinetics of adsorption of Ag nanoparticles in the clinoptilolite, where the study of the adsorption efficiency under optimized conditions will be carried out and subsequently it will be evaluated in relation to the removal of heavy metals and their antibacterial effects. 


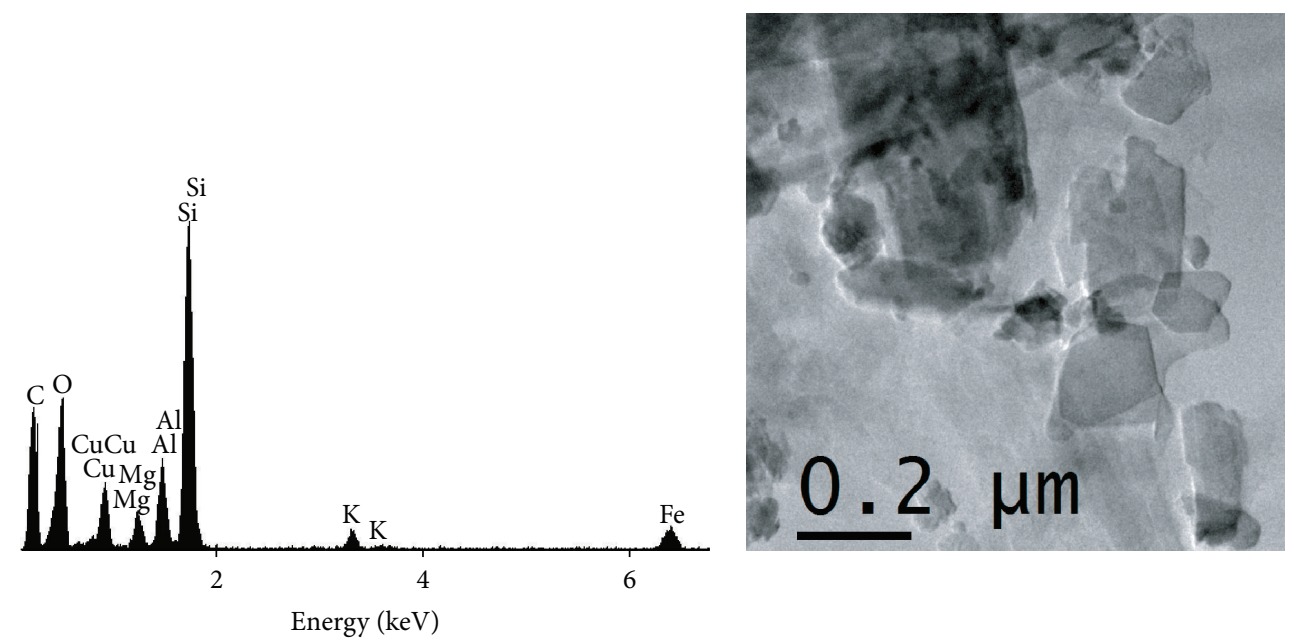

(a)

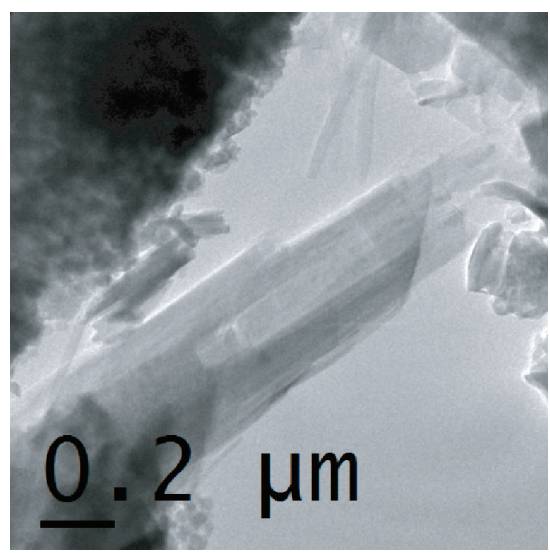

(c)

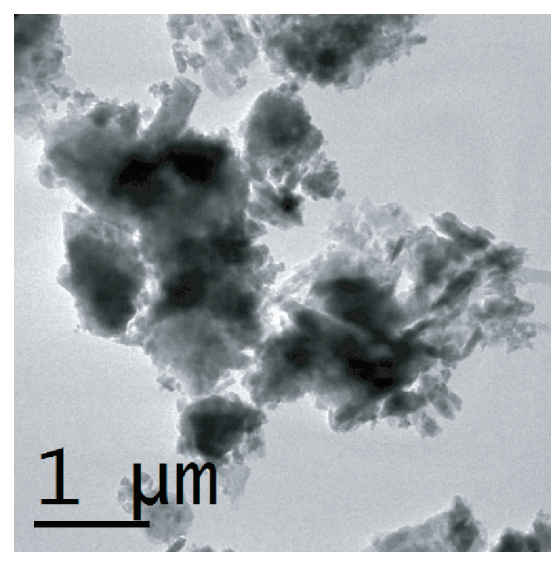

(d)

FIGURE 1: (a) EDS chemical analysis of the natural zeolite. ((b), (c), and (d)) Bright field TEM images corresponding to the clinoptilolite, mordenite, and feldspar phases, respectively.

\section{Experimental Procedure}

The zeolite type clinoptilolite was collected from Oaxaca, Mexico. It was milled and sieved to $-120+60$ mesh $(2 \mathrm{~mm})$.

Subsequently, it was washed with deionized water to remove any impurities and dried at $80^{\circ} \mathrm{C}$ for 24 hours. $\mathrm{Ag}$ nanoparticles solutions were previously prepared according to the chemical reduction method reported in previous work [13]. The composites preparation was carried out by immersing of $1 \mathrm{~g}$ of zeolite in $1 \mathrm{~mL}$ of $\mathrm{Ag}$ nanoparticles with concentrations of $1,2,3$, and $4 \mathrm{mg} \mathrm{L}^{-1}$. Each sample was magnetically stirred for different times in intervals of $30 \mathrm{~min}$ from 0 to $180 \mathrm{~min}$. In order to identify the $\mathrm{Ag}$ structure in the composite, DRX patterns were obtained using a Rigaku Ultima IV diffractometer. The experimental data of the adsorption behavior in zeolites and their chemical characterization were conducted by an atomic absorption spectrophotometry (AAS) technique using Perkin Elmer 3100 equipment. In the case of chemical characterization, the sample was previously subjected to a digestion and dilution process using lithium metaborate, $\mathrm{LiBO}_{2}$. The characterization was complemented by an energy dispersive (EDS) analysis and the AgNPs distribution on the zeolite was studied using a Philips Tecnai F20 transmission electron microscope with a field-emission gun attachment.

\section{Results and Discussion}

The natural zeolite obtained from Oaxaca was structurally characterized and presented in a recent paper [13]. However, the chemical characterization of the material is just presented in the following lines of text. Figure 1(a) shows a chemical analysis obtained by EDX, which identified typical elements as $\mathrm{Si}, \mathrm{Al}, \mathrm{O}, \mathrm{Mn}, \mathrm{K}$, and $\mathrm{Ca}$ present in the clinoptilolite.

Figures 1(b), 1(c), and 1(d) show bright field images corresponding to the morphologies of the clinoptilolite, mordenite, and feldspars phases reported on the structural characterization of the mineral [13].

It is important to mention that the chemical analysis was obtained by EDX technique. However, experimentally, the chemical characterization of the zeolite was performed using the metaborate method as digestion and dilution mechanism. Subsequently, the absorption spectrophotometry 


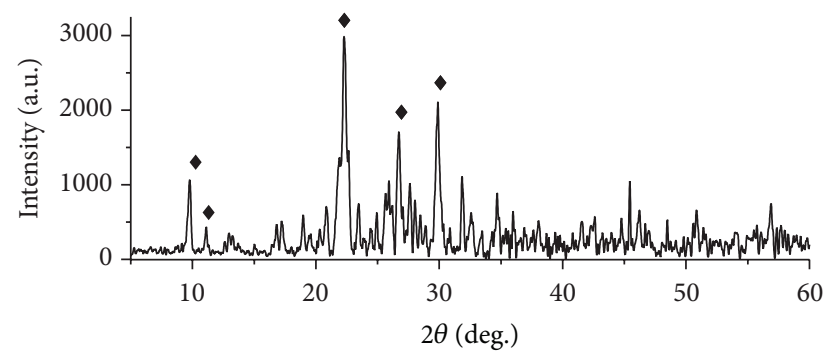

(a)

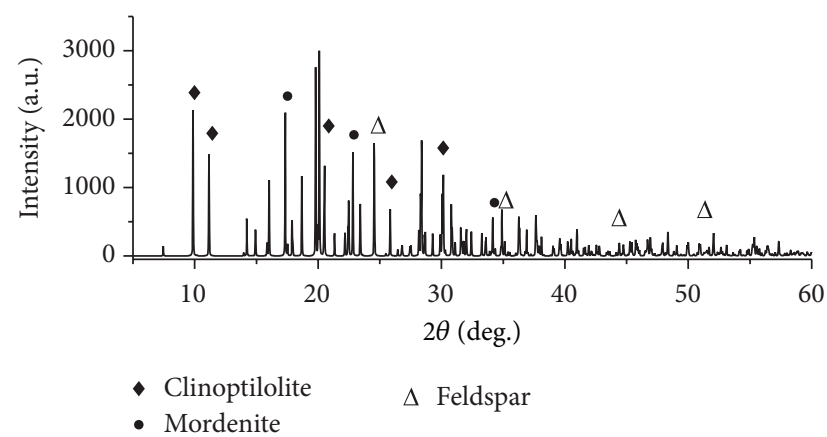

(b)

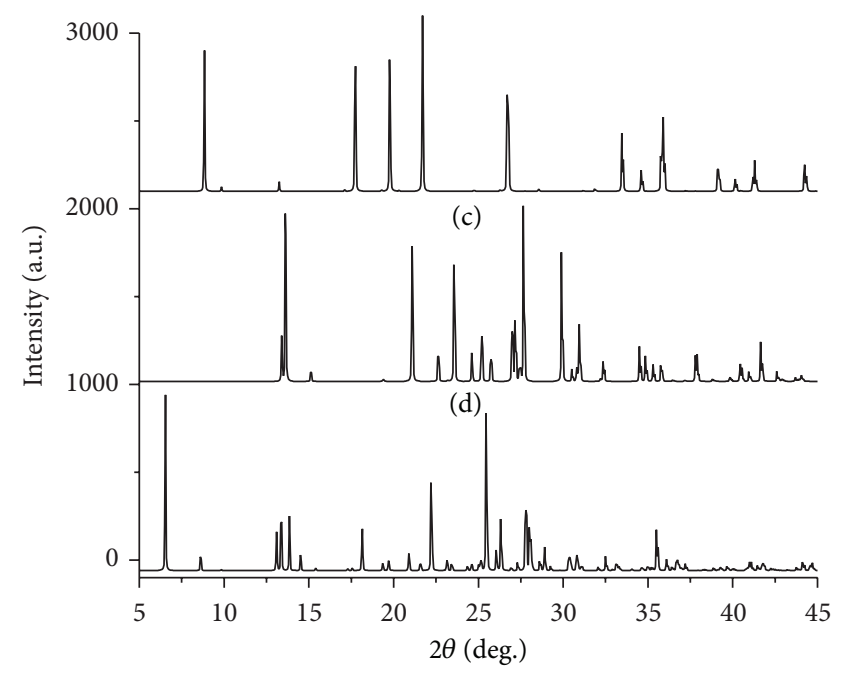

(e)

FIGURE 2: XRD patterns of the natural zeolite obtained (a) experimentally and (b) by simulation of the crystalline phases. (c)-(e) Simulated $\mathrm{XRD}$ patterns of the clinoptilolite, mordenite, and feldspar, respectively.

TABLE 1: Chemical composition of natural zeolite.

\begin{tabular}{lcccc}
\hline Element & Experimental & \multicolumn{2}{c}{ EDS } \\
\% W zeolite & \\
\hline $\mathrm{Si}$ & 81.7 & 64.46 & $\mathrm{SiO}_{2}$ & 77.04 \\
$\mathrm{Al}$ & 8.01 & 8.75 & $\mathrm{Al}_{2} \mathrm{O}_{3}$ & 13.2 \\
$\mathrm{~K}$ & 6.04 & 11.53 & $\mathrm{~K}_{2} \mathrm{O}$ & 6.42 \\
$\mathrm{Fe}$ & 1.145 & 12.34 & $\mathrm{FeO}$ & 0.66 \\
$\mathrm{Ca}$ & 1.2 & 2.91 & $\mathrm{CaO}$ & 0.75 \\
$\mathrm{Mg}$ & 0.725 & & $\mathrm{MgO}$ & 0.53 \\
$\mathrm{Na}$ & 1.18 & & $\mathrm{Na}_{2} \mathrm{O}$ & 1.4 \\
\hline
\end{tabular}

(AAS) technique was used to quantify the elements present in the zeolite. Table 1 indicates a comparison between the quantification procedures of zeolite elements obtained by EDX and AAS techniques. Evidently, there are significant variations due to the nature of these quantitative techniques. The relation $\mathrm{Si} / \mathrm{Al}$ observed in chemical analysis was 10.19 and 7.37 in each case. It has been reported that minerals with high $\mathrm{Si} / \mathrm{Al}$ ratio offer excellent cation exchange [14]. Therefore, it can be affirmed that zeolite exhibits an excellent behavior in cation-exchange capacity. This result will be evaluated through the study of the adsorption kinetics presented in this research.

Figure 2(a) shows the experimental XRD pattern corresponding to the zeolite. The main phase present in the natural zeolite is the clinoptilolite; the higher intensities observed are attributed to the mineralogical phase. In Figure 2(b), the simulated XRD can be observed where concordance between the experimental and simulated intensities is verified. Therefore, the three phases (clinoptilolite, mordenite, and feldspar) proposed for the XRD pattern simulation are present in the zeolite [13]. Additionally, individual XRD patterns for each phase are presented in Figures 2(c)-2(e).

Figure 3 shows the AgNPs adsorption by clinoptilolite. The highest rates of adsorption are observed in sample with concentration of $2 \mathrm{mg} \mathrm{L}^{-1}$. The value of maximum adsorption is $90 \%$ and is conducted in a time of $150 \mathrm{~min}$. In subsequent values to $150 \mathrm{~min}$ and $4 \mathrm{mg} \mathrm{L}^{-1}$, no relevant changes are presented in the adsorption rates. This result suggests that zeolite saturation depends directly on the effective diameter of the nanoparticles and consequently the volume of AgNPs used for adsorption. Some theoretical models are presented below to investigate the mechanism of AgNPs sorption onto clinoptilolite.

\section{Theoretical Models}

The theoretical models reveal the solid/liquid adsorption processes. These processes are generally due to a cation-exchange reaction between adsorbent and adsorbate related to masstransport processes or particles diffusion in macropores or micropores [15]. Pseudo-first-order, pseudo-second-order, Elovich, and intraparticle diffusion models are presented to describe and support the adsorption kinetic behavior of AgNPs. 


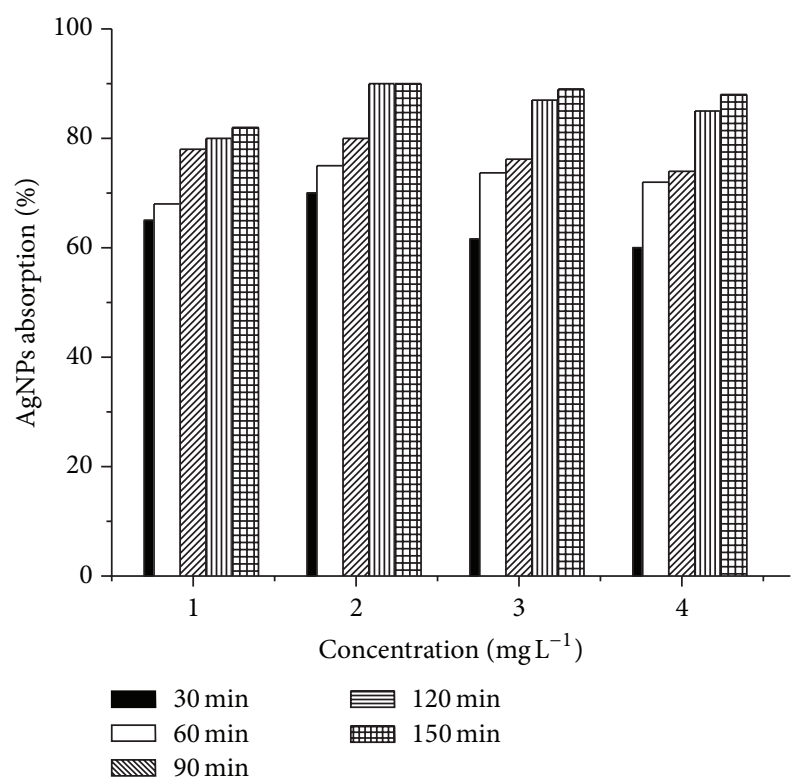

FIgURE 3: Efficiency adsorption plot of AgNPs on the zeolite.

4.1. Lagergren Pseudo-First-Order Model. The pseudo-firstorder adsorption model is defined by the Lagergren equation $[16,17]$ :

$$
\frac{d q}{d t}=K_{1}\left(q_{e}-q_{t}\right)
$$

where $q_{e}$ and $q_{t}$ are the amounts of AgNPs sorbed at equilibrium and a given time $t$. The pseudo-first-order adsorption rate coefficient is $k_{1}\left(\mathrm{~min}^{-1}\right)$. Solving the differential equation for boundary conditions, $t=0, q_{t}=0, t=t$, and $q_{t}=q_{t}$, this equation can be expressed in the lineal form as

$$
\ln \left(q_{e}-q_{t}\right)=\ln q_{e}-k t .
$$

4.2. Pseudo-Second-Order Model. The pseudo-second-order kinetic equation may be expressed as

$$
\frac{d q}{d t}=K_{2}\left(q_{e}-q_{t}\right)^{2}
$$

Using the integration limits employed in the first-order equation, this equation can be written in the following way [18]:

$$
\frac{t}{q_{t}}=\frac{1}{k_{2} q_{e}^{2}}-\frac{1}{q_{e}} t .
$$

In this case, $k_{2}$ represent the rate constant for pseudo-secondorder sorption $\left(\mathrm{g} \mathrm{mg}^{-1} \mathrm{~min}^{-1}\right)$.

4.3. Elovich Model. This mathematical model has been widely used in description of the kinetics of adsorption of a solute in a liquid phase from a solid sorbent. The mathematical expression that governs the behavior of this model is

$$
\frac{d q_{t}}{d t}=\alpha e^{-\beta q_{t}}
$$

Integrating (3) and using the boundary conditions pseudofirst-order model, Elovich or Roginsky and Zeldovich equation would be [19]

$$
q_{t}=\frac{1}{\beta} \ln (\alpha \beta)+\frac{1}{\beta} \ln t,
$$

where $\alpha$ is the initial adsorption rate $\left(\mathrm{mg}^{-1} \mathrm{~g}^{-1} \cdot \mathrm{min}\right)$ and $\beta$ is the desorption constant $\left(\mathrm{g} \cdot \mathrm{mg}^{-1}\right)$. In this case, $\beta$ is described in terms of surface area covered and the activation energy derived from the chemisorption by the adsorbent.

4.4. Intraparticle Diffusion Model. The other kinetic equation is the intraparticle diffusion model, given by

$$
q_{t}=k_{i} \sqrt{t}+C_{i}
$$

where $q_{t}$ describes the amount per unit mass of nanoparticles adsorbed by the zeolite at time $t, k_{i}\left(\mathrm{mg} \cdot \mathrm{g}^{-1} \cdot \mathrm{min}^{-0.5}\right)$ is the rate constant of intraparticle diffusion, and $C_{i}$ is the intercept $[20,21]$.

Figure 4(a) shows the Lagergren kinetics adsorption model of AgNPs into clinoptilolite. In this case, a significant correlation between the experimental results and $R^{2}$ factor is observed (Table 2). The highest correlation values for the first-order Lagergren model are presented in the concentrations of 3 and $4 \mathrm{mg} \mathrm{L}^{-1}$. This result supports the experimental values shown in Figure 4 where the adsorption efficiency values are similar in both cases and their behavior is linear. Of the employed theoretical models, the pseudo-second-order model (Figure 4(b)) presents the highest correlation values which are of the order of 0.99 . Therefore, the second-order model describes with greater accuracy the adsorption process. This represents chemisorption or chemical adsorption due to the formation of chemical bonds between adsorbent and adsorbate in a monolayer on the surface $[16,22]$.

In this sense, the Elovich model (Figure 4(c)) also represents a chemisorption phenomenon. Nonetheless, this model is applied to systems with heterogeneous surfaces and different activation energies [7,23]. Consequently, the correlation coefficients obtained by the Elovich model $\left(0.88164<R^{2}<\right.$ 0.93829 ) exhibit less agreement with the experimental values obtained. The intraparticle diffusion model (Figure 4(d)) presents $R^{2}$ values in the range of $0.911<R^{2}<0.9523$ (Table 2). This result can be attributed to the homogeneous porous structure of the zeolite. Therefore, this model also describes the transport and diffusion mechanism of solute through the internal structure of the pores of adsorbent (clinoptilolite).

Figures 5(a) and 5(b) show a bright field TEM image, in which the homogeneous distribution of the AgNPs on the zeolite surface can be appreciated. This result verifies that the chemisorption phenomenon describes the adsorption process carried out by the mineral. This is due to the AgNPs interaction with the active sites of the zeolite and the formation of a unimolecular layer uniformly distributed on the surface of the zeolite is observed (Figure 4(c)). Finally, Figure 5(d) shows the chemical analysis made from the composite, in which the incorporation of silver nanoparticles 


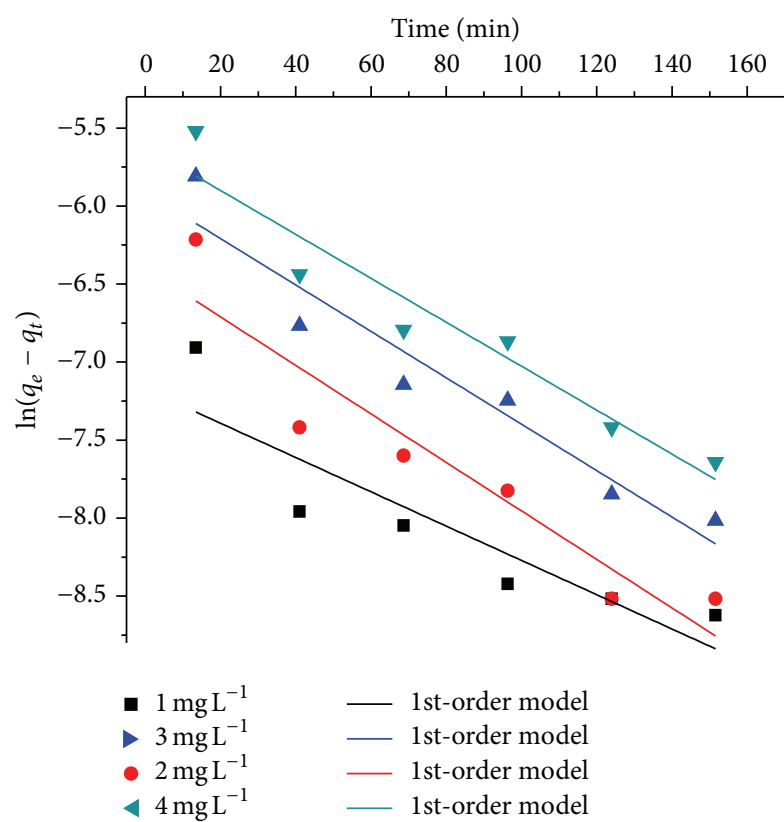

(a)

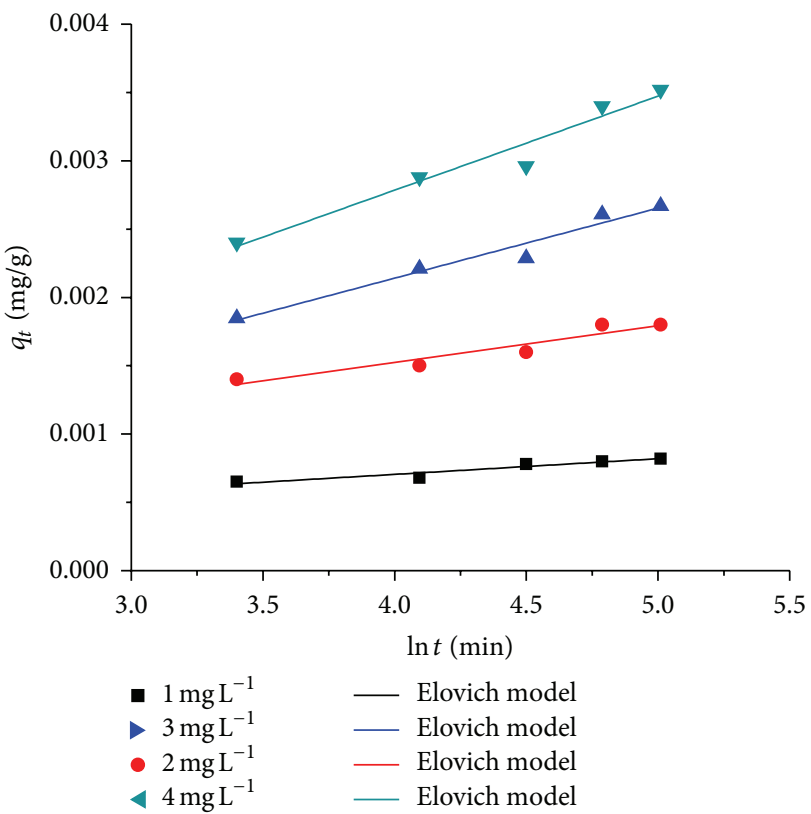

(c)

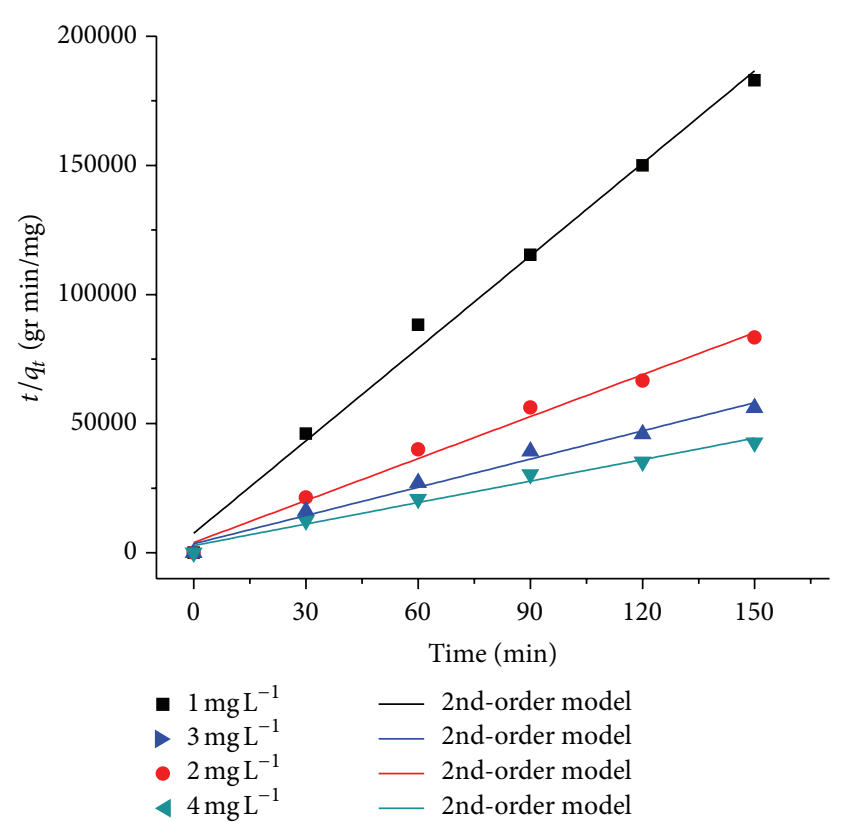

(b)

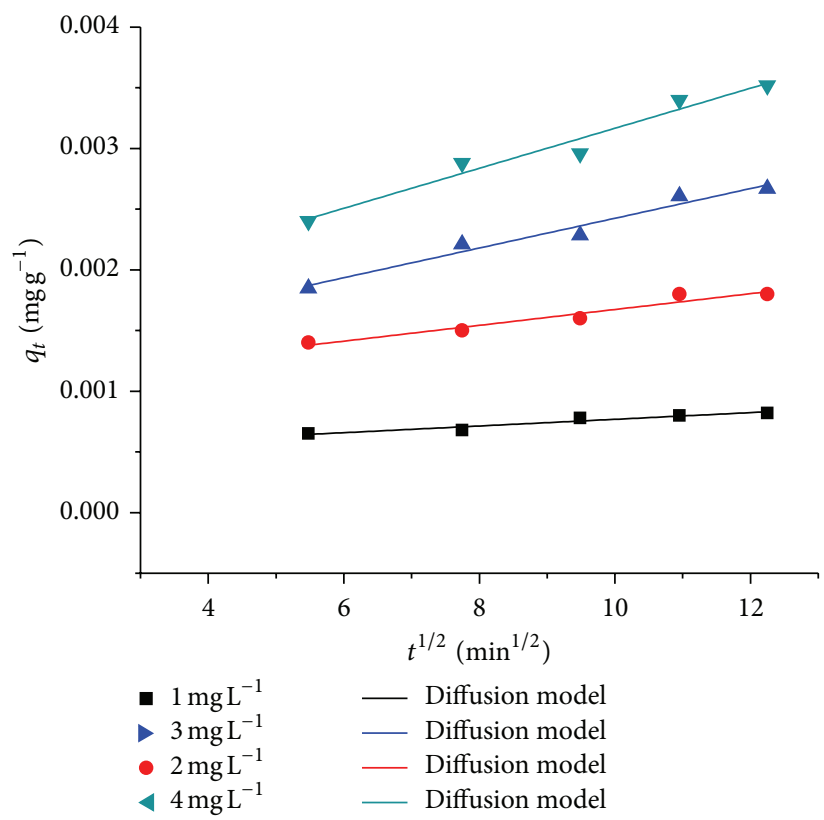

(d)

FIGURE 4: Graphs of the theoretical models corresponding to (a) Lagergren pseudo-first-order model, (b) pseudo-second-order model, (c) Elovich, and (d) intraparticle diffusion model.

is found. In this sense, it can be deduced that the process of impregnation of the particles was carried out efficiently since the adsorbate was distributed throughout the zeolite surface.

\section{Conclusions}

The interaction between the zeolite and the AgNPs is described through a chemisorption process. In this research, the characteristics of this process are observed and verified by adsorption theoretical models. Pseudo-second-order and intraparticle diffusion models present higher correlation factors with respect to the experimental values obtained. This fact supports the formation of chemical bonds between adsorbent and adsorbate in a monolayer on the zeolite surface. The homogeneous mineral porosity promotes this behavior. On the other hand, high adsorption efficiencies observed verified the affinity of the zeolite and the AgNPs. Minor particle concentrations ( 1 and $2 \mathrm{mg} \mathrm{L}^{-1}$ ) present high adsorption rates, because the pore saturation is lower, promoting the adsorption phenomenon. 
TABLE 2: Kinetic parameter obtained from theoretical adsorption models.

\begin{tabular}{|c|c|c|c|c|c|c|c|c|}
\hline \multirow{4}{*}{$\begin{array}{l}\text { Kinetic model } \\
1 \mathrm{mg} \mathrm{L}^{-1}\end{array}$} & \multicolumn{2}{|c|}{$\begin{array}{l}\text { Lagergren first-order } \\
\left(K_{1}\right) \mathrm{min}^{-1}\end{array}$} & \multicolumn{2}{|c|}{$\begin{array}{l}\text { Pseudo-second-order } \\
K_{2}\left(\mathrm{~g} \mathrm{mg}^{-1} \mathrm{~min}^{-1}\right) \\
q_{e}\left(\mathrm{mgg}^{-1}\right)\end{array}$} & \multicolumn{2}{|c|}{$\begin{array}{c}\text { Elovich } \\
\alpha\left(\mathrm{mg} \mathrm{g}^{-1} \min \right) \\
\beta\left(\mathrm{g} \mathrm{mg}^{-1}\right)\end{array}$} & \multicolumn{2}{|c|}{$\begin{array}{l}\text { Intraparticle } \\
\quad \text { diffusion } \\
K_{i}\left(\mathrm{mg} \cdot \mathrm{g}^{-1} \cdot \mathrm{min}^{-0.5}\right)\end{array}$} \\
\hline & \multirow{2}{*}{$K_{1}$} & \multirow{2}{*}{0.023} & $K_{2}$ & $1.88 E+02$ & $\alpha$ & 73690.88 & $C_{i}$ & $4.93 E-04$ \\
\hline & & & $q_{e}$ & $8.38 E-04$ & $\beta$ & 0.000115 & $K_{i}$ & $2.76 E-05$ \\
\hline & $R^{2}$ & 0.762 & $R^{2}$ & 0.99108 & $R^{2}$ & 0.89589 & $R^{2}$ & 0.91193 \\
\hline \multirow{3}{*}{$2 \mathrm{mg} \mathrm{L}^{-1}$} & \multirow{2}{*}{$K_{1}$} & \multirow{2}{*}{0.032} & $K_{2}$ & $7.34 E+01$ & $\alpha$ & $1.98 E+04$ & $C_{i}$ & 0.00102 \\
\hline & & & $q_{e}$ & $1.85 E-03$ & $\beta$ & $2.69 E-04$ & $K_{i}$ & $6.52 E-05$ \\
\hline & $R^{2}$ & 0.857 & $R^{2}$ & 0.98635 & $R^{2}$ & 0.88164 & $R^{2}$ & 0.92399 \\
\hline \multirow{3}{*}{$3 \mathrm{mg} \mathrm{L}^{-1}$} & \multirow{2}{*}{$K_{1}$} & \multirow{2}{*}{0.031} & $K_{2}$ & $3.78 E+01$ & $\alpha$ & $2.33 E+03$ & $C_{i}$ & 0.0012 \\
\hline & & & $q_{e}$ & $2.75 E-03$ & $\beta$ & $5.13 E-04$ & $K_{i}$ & $1.22 E-04$ \\
\hline & $R^{2}$ & 0.907 & $R^{2}$ & 0.98026 & $R^{2}$ & 0.94803 & $R^{2}$ & 0.95313 \\
\hline \multirow{3}{*}{$4 \mathrm{mg} \mathrm{L}^{-1}$} & \multirow{2}{*}{$K_{1}$} & \multirow{2}{*}{0.029} & $K_{2}$ & $2.72 E+01$ & $\alpha$ & $1.53 E+03$ & $C_{i}$ & 0.00152 \\
\hline & & & $q_{e}$ & $3.61 E-03$ & $\beta$ & $6.88 E-04$ & $K_{i}$ & $1.65 E-04$ \\
\hline & $R^{2}$ & 0.908 & $R^{2}$ & 0.97719 & $R^{2}$ & 0.93829 & $R^{2}$ & 0.95237 \\
\hline
\end{tabular}

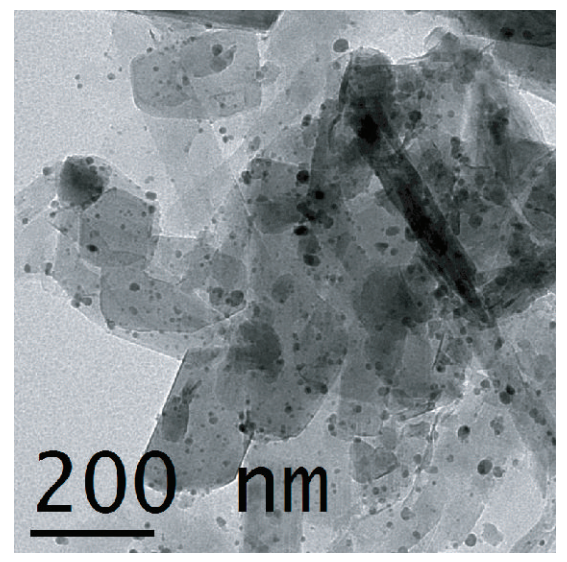

(a)

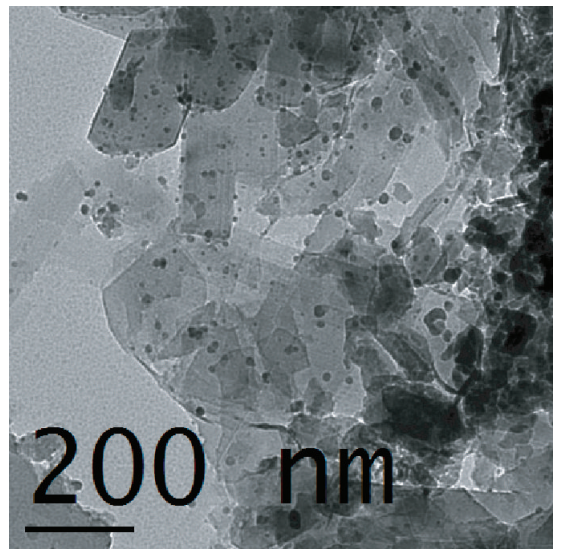

(b)

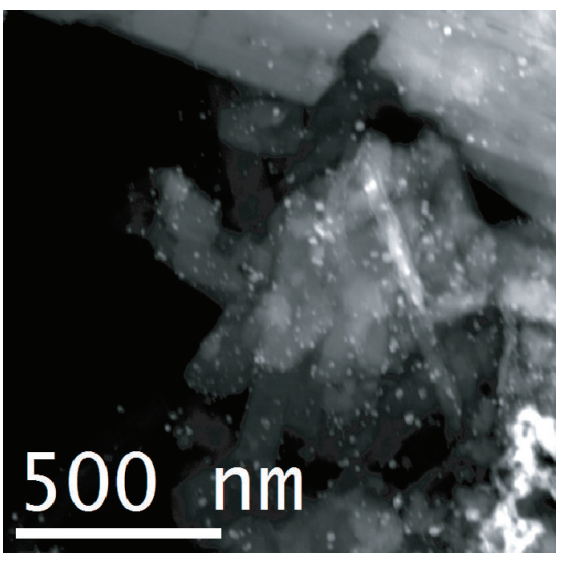

(c)

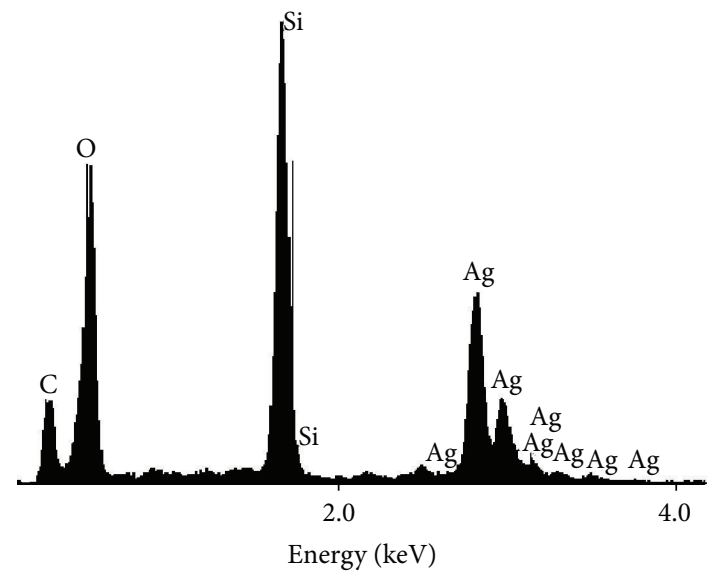

(d)

Figure 5: ((a) and (b)) Bright field TEM and (c) STEM images corresponding to the AgNPs distribution onto the zeolite surface. (d) EDS analysis of the zeolite-AgNPs material. 


\section{Conflict of Interests}

The authors declare that there is no conflict of interests regarding the publication of this paper.

\section{References}

[1] S. K. Talkhoncheh and M. Haghighi, "Syngas production via dry reforming of methane over Ni-based nanocatalyst over various supports of clinoptilolite, ceria and alumina," Journal of Natural Gas Science and Engineering, vol. 23, pp. 16-25, 2015.

[2] N. Ajoudanian and A. Nezamzadeh-Ejhieh, "Enhanced photocatalytic activity of nickel oxide supported on clinoptilolite nanoparticles for the photodegradation of aqueous cephalexin," Materials Science in Semiconductor Processing, vol. 36, pp. 162169, 2015.

[3] E. Donati, C. M. Polcaro, P. Ciccioli, and E. Galli, “The comparative study of a laccase-natural clinoptilolite-based catalyst activity and free laccase activity on model compounds," Journal of Hazardous Materials, vol. 289, pp. 83-90, 2015.

[4] I. Rodríguez-Iznaga, V. Petranovskii, F. Castillón-Barraza, and B. Concepción-Rosabal, "Copper-silver bimetallic system on natural clinoptilolite: thermal reduction of $\mathrm{Cu}^{2+}$ and $\mathrm{Ag}^{+}$ exchanged," Journal of Nanoscience and Nanotechnology, vol. 11, no. 6, pp. 5580-5586, 2011.

[5] F. S. Fateminia and C. Falamaki, "Zero valent nano-sized iron/clinoptilolite modified with zero valent copper for reductive nitrate removal," Process Safety and Environmental Protection, vol. 91, no. 4, pp. 304-310, 2013.

[6] F. B. Karel, A. S. Koparal, and E. Kaynak, "Development of silver ion doped antibacterial clays and investigation of their antibacterial activity," Advances in Materials Science and Engineering, vol. 2015, Article ID 409078, 6 pages, 2015.

[7] D. Guaya, C. Valderrama, A. Farran, C. Armijos, and J. L. Cortina, "Simultaneous phosphate and ammonium removal from aqueous solution by a hydrated aluminum oxide modified natural zeolite," Chemical Engineering Journal, vol. 271, pp. 204213, 2015.

[8] A. Pourtaheri and A. Nezamzadeh-Ejhieh, "Enhancement in photocatalytic activity of $\mathrm{NiO}$ by supporting onto an Iranian clinoptilolite nano-particles of aqueous solution of cefuroxime pharmaceutical capsule," Spectrochimica Acta Part A: Molecular and Biomolecular Spectroscopy, vol. 137, pp. 338-344, 2015.

[9] M. A. Zayed, S. E. M. El-Begawy, and H. E. S. Hassan, "Enhancement of stabilizing properties of double-base propellants using nano-scale inorganic compounds," Journal of Hazardous Materials, vol. 227-228, pp. 274-279, 2012.

[10] A. Nezamzadeh-Ejhieh and K. Shirvani, "CdS loaded an Iranian clinoptilolite as a heterogeneous catalyst in photodegradation of p-aminophenol," Journal of Chemistry, vol. 2013, Article ID 541736, 11 pages, 2013.

[11] A. Ortiz-Polo, R. M. Richards-Uribe, E. M. Otazo-Sánchez et al., "New organo-inorganic materials for water contaminants remediation," in Materials Research Society Symposium Proceedings, vol. 1007, pp. 129-136, 2008.

[12] M. J. Jiménez-Cedillo, M. T. Olguín, C. Fall, and A. Colín, "Adsorption capacity of iron- or iron-manganese-modified zeolite-rich tuffs for As(III) and As(V) water pollutants," Applied Clay Science, vol. 54, no. 3-4, pp. 206-216, 2011.

[13] A. Ruíz-Baltazar, R. Esparza, R. Pérez, and G. Rosas, "Synthesis of Ag nanoparticles-clinoptilolite composite by homogeneous and heterogeneous nucleation," Materials Science Forum, vol. 755, pp. 97-103, 2013.

[14] F. E. Celik, T.-J. Kim, and A. T. Bell, "Effect of zeolite framework type and Si/Al ratio on dimethoxymethane carbonylation," Journal of Catalysis, vol. 270, no. 1, pp. 185-195, 2010.

[15] L. Mihaly-Cozmuta, A. Mihaly-Cozmuta, A. Peter et al., "Adsorption of heavy metal cations by Na-clinoptilolite: equilibrium and selectivity studies," Journal of Environmental Management, vol. 137, pp. 69-80, 2014.

[16] S. Sen Gupta and K. G. Bhattacharyya, "Kinetics of adsorption of metal ions on inorganic materials: a review," Advances in Colloid and Interface Science, vol. 162, no. 1-2, pp. 39-58, 2011.

[17] E. Goldani, C. C. Moro, and S. M. Maia, "A study employing differents clays for Fe and $\mathrm{Mn}$ removal in the treatment of acid mine drainage," Water, Air, \& Soil Pollution, vol. 224, article 1401, 2013.

[18] Y. S. Ho and G. McKay, "Pseudo-second order model for sorption processes," Process Biochemistry, vol. 34, no. 5, pp. 451465, 1999.

[19] R. Cortés-Martínez, M. T. Olguín, and M. Solache-Ríos, "Cesium sorption by clinoptilolite-rich tuffs in batch and fixedbed systems," Desalination, vol. 258, no. 1-3, pp. 164-170, 2010.

[20] A. Olad, S. Ahmadi, and A. Rashidzadeh, "Removal of Nickel (II) from aqueous solutions with polypyrrole modified clinoptilolite: kinetic and isotherm studies," Desalination and Water Treatment, vol. 51, no. 37-39, pp. 7172-7180, 2013.

[21] D. O’Carroll, B. Sleep, M. Krol, H. Boparai, and C. Kocur, "Nanoscale zero valent iron and bimetallic particles for contaminated site remediation," Advances in Water Resources, vol. 51, pp. 104-122, 2013.

[22] M. Anari-Anaraki and A. Nezamzadeh-Ejhieh, "Modification of an Iranian clinoptilolite nano-particles by hexadecyltrimethyl ammonium cationic surfactant and dithizone for removal of $\mathrm{Pb}$ (II) from aqueous solution," Journal of Colloid and Interface Science, vol. 440, pp. 272-281, 2015.

[23] Y. Yu, J. G. Shapter, R. Popelka-Filcoff, J. W. Bennett, and A. V. Ellis, "Copper removal using bio-inspired polydopamine coated natural zeolites," Journal of Hazardous Materials, vol. 273, pp. 174-182, 2014. 

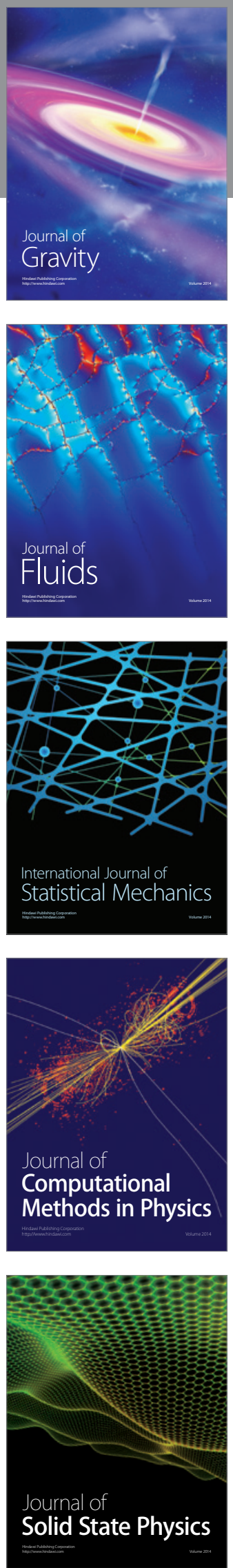

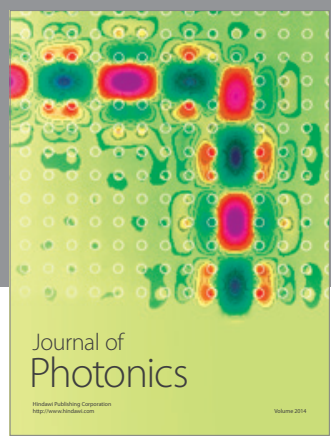

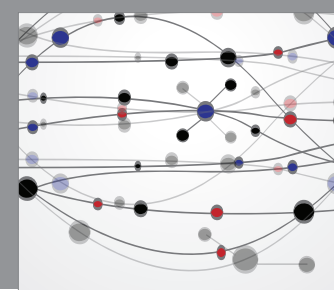

The Scientific World Journal

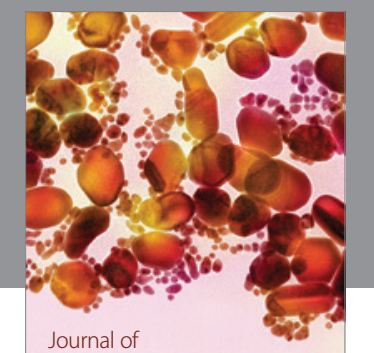

Soft Matter
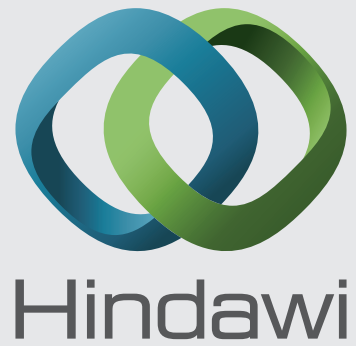

Submit your manuscripts at

http://www.hindawi.com
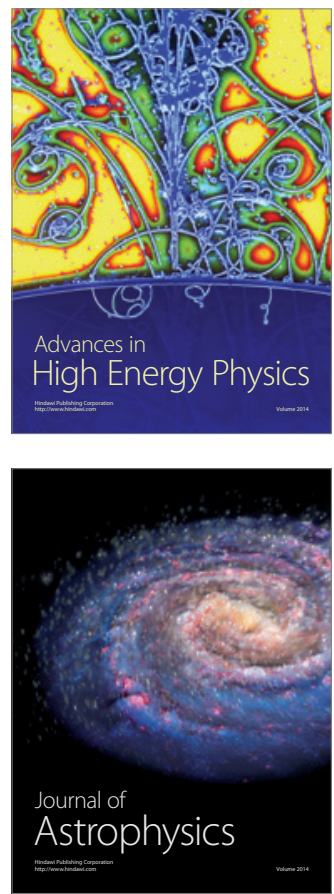
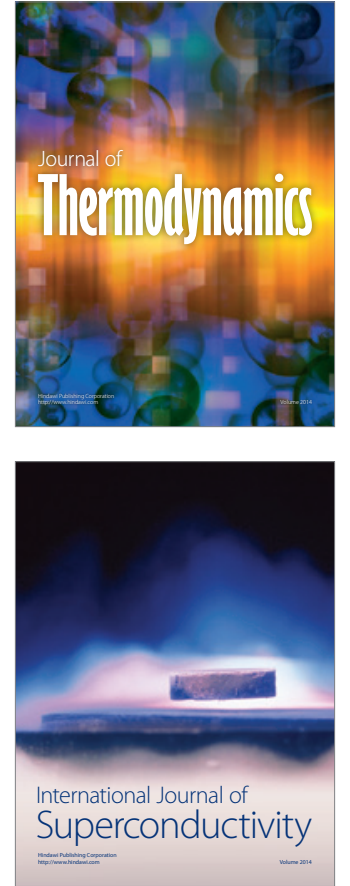
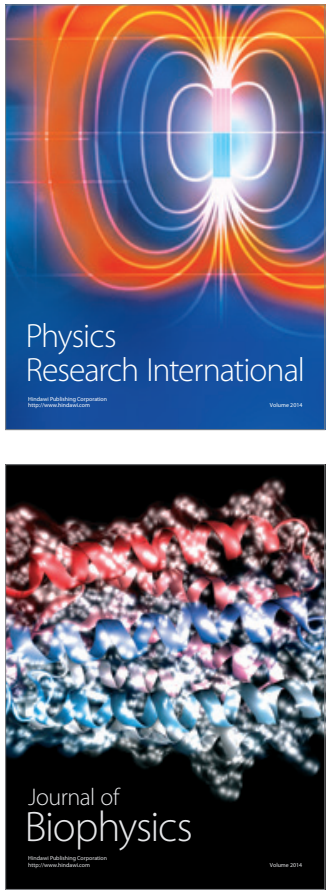
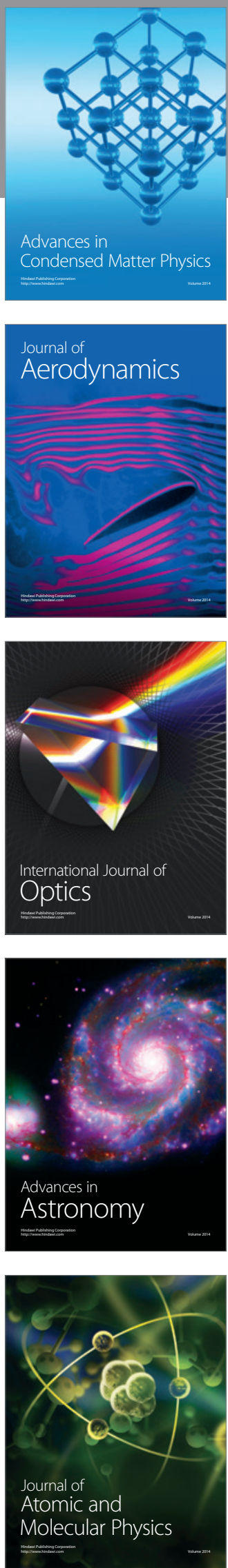